\title{
Dermatophytosis among Elementary School Students in Jatinangor West Java
}

\author{
Dwi Bandang Saskia, ${ }^{1}$ Lies Marlysa Ramali, ${ }^{2}$ Ramlan Sadeli ${ }^{3}$ \\ ${ }^{1}$ Faculty of Medicine Universitas Padjadjaran, ${ }^{2}$ Department of Dermatovenereology Faculty of \\ Medicine Universitas Padjadjaran/Dr. Hasan Sadikin General Hospital Bandung, ${ }^{3}$ Department of \\ Microbiology and Parasitology Faculty of Medicine Universitas Padjadjaran
}

\begin{abstract}
Background: Dermatophytosis is a common skin disease in tropical countries. In Indonesia, the incidence of dermatophytosis is quite high. Epidemiological studies showed that prevalence of dermatophytosis in children were higher than in adults. The aim of this study was to identify dermatophytosis cases among elementary school students in Jatinangor West Java.

Methods: A descriptive study was carried out, involving 391 students aged 6-16 years from four elementary schools in Jatinangor West Java, who were selected by multi-stage sampling method. Six classes were chosen from each school. In every class, students were chosen to obtain the minimum number of samples. The inclusion criteria was elementary school students who were willing to participate in this study. The exclusion criteria were students who did not attend school at the time when the study wasperformed. The study's procedure consisted of six steps i.e. preparation, interview, screening, physical examination, specimen collection and microscopic examination. The collected data was processed by calculating the frequency and percentage.

Results: The study discovered that out of 391 students, 197 suffered from non specific skin lesions. After confirmed by a dermatologist, three students were suspected to have dematophytosis lesion. From microscopical examinations by a microbiologist, two students had positive dermatophyte hyphae. The number of dermatophytosis cases in elementary school students, in Jatinangor was $0.5 \%(2 / 391)$.

Conclusions: The incidence of dermatophytosis cases in this study is relatively low compared with other studies. Clinical features are tinea corporis. Both patients with positive dermatophyte hyphae are ten -year -old females. [AMJ.2016;3(2):165-9]
\end{abstract}

Keywords: Dermatophytosis, elementary school students, tinea corporis

\section{Introduction}

Common fungal infection is a superficial fungal infection which affects the skin. While superficial fungal infection is a common infection occurring worldwide this is most often caused by dermatophyte fungi which are called dermatophytosis. ${ }^{1-4}$ This infection affects thepart of body that contains keratin (such as skin, hair, and nail). ${ }^{1,4}$ Dermatophyte infection appears after direct and indirect contact with patients. ${ }^{3}$ Although dermatophytosis is a contagious disease, it is not life-threatening. ${ }^{1-3}$ The transmission of dermatophytosis in humans is commonly from animals to humans, from humans to other humans, and from soil to humans. Many factors contribute to the occurrence of dermatophytosis such as lack of personal hygiene, hot and humid climate, availability of source of infection in the surrounding areas, long term use of antibiotic drugs and steroid, age factor and socioeconomic status. ${ }^{5}$

Furthermore, dermatophytosis is common throughout the world especially in tropical countries. $^{6}$ About $20-25 \%$ of the population in the world suffers from this disease and the incidence continues to rise. ${ }^{2,7} \mathrm{~A}$ study in Arochukwu, Nigeria ${ }^{5}$ revealed that out of a total of 4.287 elementary school students, 1.740 males and 2.547 females were examined for clinical signs of dermatophytosis. There were $873(20.4 \%)$ students consisting of 505 males and 368 females who had

Correspondence: Dwi Bandang Saskia, Faculty of Medicine, Universitas Padjadjaran, Jalan Raya Bandung-Sumedang Km.21, Jatinangor, Sumedang, Indonesia, Phone: +6285721393696, Email: dwibandangsaskia@gmail.com 
dermatophytosis lesion. Another study from Dar es SalaamTanzania, ${ }^{8}$ discovered that out of 420 elementary school students, 48 were positive with this disease. Different results from Amazonas, Brazil showed that out of 590 samples analysed, 210 showed positive dermatophytosis. ${ }^{9}$ Other broad literature resources showed different results from different parts of theworld. ${ }^{2,5,8}$

In Indonesia, ${ }^{10}$ dermatophytosis infection becomes a national problem because the number of patients is quite high. A study conducted by Kurniati ${ }^{10}$ discovered that incidence of dermatophytosis was the highest among other superficial dermatomycosis infections. Additionally, epidemiological studies showed that prevalence of dermatophytosis in children was higher than in adults because they were more susceptible to infection. ${ }^{5}$ In accordance with the previous explanation, the objective of this study was to identify the dermatophytosis infection among elementary school students in Jatinangor West Java.

\section{Methods}

A descriptive study was performed involving all elementary schools in Jatinangor from thefirst grade until the sixth grade in SeptemberOctober 2013. The total number of sample needed was 385 respondents and a multistage sample technique was carried out to fulfill the number of sample. Out of a total of 29 elementary schools in Jatinangor subdistrict, four elementary schools were selected, namely SDN Cikuda, SDN Sinarjati, SDN Jatiroke I and SDN Cikopo I. Next, six classes were selected from each school and from these classes students were selected to obtain the minimum number of sample.

The inclusion criteria were elementary school students who were willing to participate in this study. The exclusion criteria were students who did not attend school at the time when the study was conducted .This study consisted of two variables, namely the dermatophytosis case and the characteristics of the dermatophytosis patients. The dermatophytosis case was defined as the finding of dermatophytosis lesion in the physcal examination and the description of a long septate and branched hypha/arthrosphore in the microscopic examination. Furthermore, the characteristics of the dermatophytosis patients comprised three components, i.e. age, sex and clinical feature. The collected data were processed by calculating the frequency and percentage.

The study's procedure consisted of six steps regarding preparation, interview, screening, physical examination, specimen collection and microscopic examination. The six steps were: 1) The activites of the preparation process such as giving explanations to the principal of the selected schools about the study and requesting consent from the respective school principal. Furthermore, the sampling process was performed to all elementary school children from the selected classes to meet the required number of sample (Table $1)$, then, an interview was carried out to all the selected samples; 2) Screening was carried out to all samples to detect whether there were skin diseases or not before a physical examination was performed, 3) Out of the 391 samples, 197 samples had skin lesion. Those samples performed anamnesis and physical examinations supervised by adermatovenerologist to confirm whether there was dermatophytosis lesion or not. Lesion on the scalp was confirmed by Wood's lamp examination. ${ }^{11}$ 4) Specimen collection for microscopic examination was carried out to

Table 1 Distribution of Samples Distribution of Samples

\begin{tabular}{lccccc}
\hline Class & SDN Cikuda & SDN Cikopo I & SDN Sinarjati & SDN Jatiroke I & Total \\
\hline I & 0 & 16 & 22 & 15 & 53 \\
II & 17 & 0 & 21 & 16 & 54 \\
III & 17 & 17 & 20 & 16 & 70 \\
IV & 17 & 16 & 25 & 18 & 76 \\
V & 17 & 17 & 22 & 17 & 73 \\
VI & 17 & 16 & 17 & 16 & 66 \\
Total & 85 & 82 & 126 & 98 & 391 \\
\hline
\end{tabular}


Dwi Bandang Saskia, Lies Marlysa Ramali, Ramlan Sadeli: Dermatophytosis among Elementary School 167 Students in Jatinangor West Java

Table 2 Distribution of Samples According to Age and Sex

\begin{tabular}{lcc}
\hline Variables & Total (N=391) & Percentage (\%) \\
\hline Age & 27 & \\
6 & 54 & 6.9 \\
7 & 67 & 13.8 \\
8 & 77 & 17.1 \\
9 & 66 & 19.7 \\
10 & 62 & 16.9 \\
11 & 28 & 15.8 \\
12 & 5 & 7.2 \\
13 & 4 & 1.3 \\
14 & 0 & 1 \\
15 & 1 & 0 \\
16 & & 0.3 \\
Sex & 200 & \\
Male & 191 & 51.2 \\
Female & 28.8 \\
\hline
\end{tabular}

the sample who had dermatophytosis lesion in various locations i.e. infected hair was plucked with tweezers, lesion on scalp was scrapped with a scalpel, lesion on skin was scrapped with adhesive tape or a blunt scalpel, and debris under infected nail was taken with a blunt scalpel. ${ }^{12-14}$ Each specimen was put into an envelop and labelled according to the identity of the respondents. 5) All specimens were taken to theMicrobiology laboratory to be identified by a microbiologist. Then, each specimen was put on an object glass, dripped with lactophenol cotton blue liquid, covered with a cover glass and warmed slide over a bunsen burner. The prepared specimen was examined through a microscope. Dermatophytosis was identified if long branched and septate hyphae or arthrospores were discovered. Afterward, the diagnostic criteria for dermatophytosis were determined in accordance with the physical examinations and microscopic findings.

All procedures in this study were approved by the Health Research Ethical Committee of the Faculty of Medicine, Universitas Padjadjaran

\section{Results}

The total of 391 students included in this study was among 6-16 years old (Table 2). The age ranged from 6 to 16 years and was not normally distributed.

The median age was 11 years and covered about $15,8 \%$ of the total sample. The number of male was similar to female with the ratio 1:1 (Table 2).

Out of 391 students from four elementary schools in Jatinangor, 197 students were suspected to have skin disorders. After physical examinations were carried out by a dermatologist, only 3 students were suspected

Table 3 Number of Dermatophytosis Cases in Elementary School Students in Jatinangor,

\begin{tabular}{lcc}
\hline Dermatophytosis & N & Percentage (\%) \\
\hline Dermatophytosis (+) & 2 & 0.5 \\
Dermatophytosis (-) & 389 & 99.5 \\
Total & 391 & 100 \\
\hline
\end{tabular}


to have dermatophytosis lesion.

Moreover, after microscopical examinations were performed by a microbiologist, this study discovered that only two students $(0.5 \%)$ had positive dermatophyte hyphae indicated by long septate hyphae. Both patients were tenyear-old female students (Table 3 ).

Both patients had lesions in the form of macules and categorized as Tinea corporis, but at different locations. One was located on her trunk and the other one on her neck.

\section{Discussion}

According to the study, many students had skin disorders such as pediculosis capitis and other skin diseases in addition to dermatophytosis. This situation was caused by poor hygiene of the school environment, since Jatinangor is a tropical area with hot and humid climate. The low number of dermatophytosis case among elementary school students in Jatinangor was caused by the absence of source of infection. The occurence and transmission of infection need the existence of infection sources and its close contact with the patients. ${ }^{6,15}$ For instance, sleeping next to pets.

The incidence of dermatophytosis cases among elementary school students in Jatinangor was relatively low compared to studies conducted by various researchers, such as a study by Adefemi et al. ${ }^{16}$ in Kwara State, Nigeria discovered that the prevalence was about 5\% (30/602). In addition, Komba and Mgonda ${ }^{8}$ in Dar es Salaam, Tanzania, stated that the prevalence was $11.4 \%$ (48/420). Those studies had a similar subject as this study. The low number of dermatophytosis cases in this study might be influenced by many factors, namely the host factor, environmental factor, and availability source of infection. ${ }^{5}$

The characteristics of both patients in this study was based on age of ten years old. The result was similar to the study conducted by Komba and Mgonda ${ }^{8}$. They discovered that dermatophytosis cases in 6-10 years old children was about 21.8\%. However, the result of this study showed that the disease affected only female respondents. Nevertheless, the result from another study showed that dermatophytosis affected male more than female. For instance, the study by Ngwogu and Otokunefor ${ }^{5}$ in Nigeria, showed that about 39\% male suffered of high prevalence of dermatophytosis . Moreover, sex is an important epidemiologic factor where dermatophytosis in male is five times greater than female. ${ }^{10}$ It may be caused by the host factor which is more active and sweating excessively.

The clinical features in this study was tinea corporis, while the study by Adefemi et al. ${ }^{16}$ showed that the majority of cases were tinea capitis followed by tinea corporis. Another study by Komba and Mgonda ${ }^{8}$ showed that the majority of cases were tinea pedis and tinea corporis. The different results by various studies were due to the different climate and behaviour. Most of the countries where the studies were conducted have hot and humid climate along the year and they always wear full-covering shoes making the higher risk to have tinea pedis. ${ }^{8}$ The different clinical features are influenced by important factors such as the infecting fungus, the site of the body infected and the keratinisation at that site. ${ }^{17}$

This study had limitations. Not all the parents allowed their children to be examined after the screening phase. This condition made the next phase, namely the physical examination, could not be conducted that led to the undetected cases of dermatophytosis.

It can be concluded that the incidence of dermatophytosis is relatively low compared with other studies. The clinical feature is tinea corporis and both patients are ten years old females.

\section{References}

1. Mitchell TG. Medical mycology. In: Brooks GF, Carroll KC, Butel JS, Morse SA, editors. Jawetz, Melnick \& Adelberg's Medical Microbiology. 24th ed. New York: The McGraw-Hill Companies; 2007. p. 626-30.

2. Ameen M. Epidemiology of superficial fungal infection. Clin Dermatol. 2010;28(2):197-201.

3. Hogg S. Essential microbiology. New Delhi,India: Wiley; 2005.

4. Hainer BL. Dermatophyte infections. Am Fam Physician. 2003;67(1):101-9.

5. Ngwogu AC, Otokunefor TV. Epidemiology of dermatophytoses in a rural community in Eastern Nigeria and review of literature from Africa. Mycopathologia. 2007;164(4):149-58.

6. Madhavi, Rao R, Jyothsna K. Mycological study of dermatophytosis in rural population. Ann Biol Res. 2011;2(3):8893.

7. Tsoumani M, Jelastopulu E, Bartzavali C, Vamvakopoulou S, Dimitracopoulos G, Anastassiou ED, et al. Changes of dermatophytoses in Southwestern Greece: an 18-year survey. Mycopathologia. 
2011;172(1):63-7.

8. Komba EV, Mgonda YM. The spectrum of dermatological disorders among primary school children in Dar es Salaam. BMC Public Health. 2010;10:765.

9. Cortez AC, de Souza JV, Sadahiro A, de Oliveira JA. Frequency and aetiology of dermatophytosis in children age 12 and under in the state of Amazonas, Brazil. Rev Iberoam Micol. 2012;29(4):223-6.

10. Kurniati, Rosita CSP. Etiopatogenesis dermatofitosis. Berkala Ilmu Kesehatan Kulit \& Kelamin. 2008;20(3):243-50.

11. Andrews MD, Burns M. Common tinea infection in children. Am Fam Physician. 2008;77(10):1415-20.

12. Schieke SM, Garg A. Superficial fungal infection. In: Goldsmith LA, Katz SI, Gilchrest BA, Paller AS, Wolff K, Leffell DJ, editors. Fitzpatrick's Dermatology in General Medicine. 8th ed. New York: The McGraw-Hill Companies; 2012. p. 2277-
87.

13. Ghannoum MA, Isham NC. Dermatophytes and dermatophytoses. In: Anaissie EJ, McGinnis MR, Pfaller MA, editors. Clinical Mycology. 1st ed. London: Churcill Livingstone Elsevier; 2009. p. 375-7.

14. Tullio V, Banche G, Panzone M, Cervetti O, Roana J, Allizond V, et al. Tinea pedis and tinea unguium in a 7-year-old-child. J Med Microbiol. 2007;56(Pt 8):1122-3.

15. Mendez-Tovar LJ. Pathogenesis of dermatophytosis and tinea versicolor. Clin dermatol. 2010;28(2):185-9.

16. Adefemi SA, Odeigah LO, Alabi KM. Prevalence of dermatophytosis among primary school children in Oke-oyi community of Kwara state. Niger J Clin Pract. 2011;14(1):23-8.

17. Degreef H. Clinical forms of dermatophytosis (ringworm infection). Mycopathologia. 2008;166(5-6):257-65. 